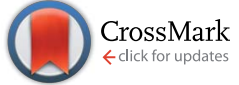

Cite this: J. Mater. Chem. A, 2016, 4, 5044

Received 23rd February 2016 Accepted 14th March 2016

DOI: 10.1039/c6ta01604a

www.rsc.org/MaterialsA

\section{A long-term corrosion barrier with an insulating boron nitride monolayer $\dagger$}

\author{
Liting Shen, $\ddagger^{\mathrm{a}}$ Yuda Zhao, $\hbar^{\mathrm{ab}}$ Yi Wang, ${ }^{\mathrm{a}}$ Ruobing Song, ${ }^{\mathrm{a}}$ Qian Yao, ${ }^{\mathrm{c}}$ Shanshan Chen ${ }^{\star d}$ \\ and Yang Chai ${ }^{\star a b}$
}

\begin{abstract}
Graphene has been demonstrated as an ultrathin and light-weight corrosion barrier because of its high impermeability. However, it fails to prevent the $\mathrm{Cu}$ corrosion over a long term because the high conductivity of graphene enables the formation of a galvanic cell and promotes the electrochemical reaction. Here we theoretically and experimentally study a boron nitride (BN) monolayer as a long-term corrosion barrier for $\mathrm{Cu}$. Our density functional theory calculations show that the potential barrier for $\mathrm{O}_{2}$ to pass through $\mathrm{BN}$ is close to that of graphene. The long-term barrier characteristics of $\mathrm{BN}$ and graphene are comparably evaluated by aging in an ambient environment for 160 days. Morphological and spectroscopic characterization shows that a BN monolayer has much better long-term barrier performance than graphene. X-ray photoelectron spectroscopy analysis shows that the $\mathrm{Cu}^{2+}$ percentage of the aging Cu sample with a BN barrier is reduced by around 15 times compared with that covered by graphene. The superior long-term barrier performance of a BN monolayer can be understood to be a result of its high impermeability and insulating characteristics, which suppress the galvanic corrosion under the ambient environment. These studies reveal that a BN monolayer is a more effective long-term corrosion barrier than graphene.
\end{abstract}

\footnotetext{
${ }^{a}$ Department of Applied Physics, The Hong Kong Polytechnic University, Hung Hom, Kowloon, Hong Kong, People's Republic of China. E-mail: ychai@polyu.edu.hk ${ }^{b}$ The Hong Kong Polytechnic University Shenzhen Research Institute, Shenzhen, People's Republic of China

'Department of Physics, Xiamen University, Xiamen, People's Republic of China ${ }^{d}$ Department of Physics, Renmin University of China, Beijing, People's Republic of China.E-mail: sschen@xmu.edu.cn

$\dagger$ Electronic supplementary information (ESI) available: The Raman characterization of $\mathrm{G}$ and $\mathrm{BN}$ on $\mathrm{Cu}$ substrate and $\mathrm{Si}$ wafer; the XPS and AFM characterization of monolayer BN; SEM images, EDS data, and Raman characterization of $\mathrm{G} / \mathrm{Cu}$ and $\mathrm{BN} / \mathrm{Cu}$ samples dipped in a $1.0 \mathrm{M} \mathrm{HNO}_{3}$ solution for $15 \mathrm{~min}$; Tafel and EIS data of $\mathrm{bCu}, \mathrm{BN} / \mathrm{Cu}$ and $\mathrm{G} / \mathrm{Cu}$ in a $0.1 \mathrm{M} \mathrm{NaCl}$ solution; XPS data of $\mathrm{BN} / \mathrm{Cu}$ and $\mathrm{G} / \mathrm{Cu}$ samples after 160 days of oxidation under ambient conditions. See DOI: 10.1039/c6ta01604a

$\$$ Liting Shen and Yuda Zhao contribute equally to this work.
}

\section{Introduction}

Metal corrosion in infrastructures caused an annual loss of around $\$ 300$ billion in the United States and $€ 200$ billion in Europe in $2014 .{ }^{1}$ It is highly desirable to develop an ultrathin corrosion barrier, which can effectively protect a metal for a long term but insignificantly affect the intrinsic properties of the materials that are protected. Graphene, an atomic-level thin layer, has been demonstrated as a corrosion barrier for metals including $\mathrm{Ni}^{2}{ }^{2} \mathrm{Cu},{ }^{2-5} \mathrm{Ag},{ }^{6-8} \mathrm{Au}^{9}$ and $\mathrm{Pt}^{10,11}$ and as a diffusion barrier for a metal-semiconductor interconnect. ${ }^{12-15}$ Hightemperature annealing and electrochemical test showed excellent barrier performance of a graphene nanosheet for a short term. ${ }^{2,16-18}$ However, Zhou et al. and Schriver et al. revealed that a graphene barrier promotes the corrosion of $\mathrm{Cu}$ in air when the exposure time is extended to several months. ${ }^{19,20}$ This corrosionpromotion process by the graphene barrier has been understood to be the result of the galvanic corrosion of the graphene$\mathrm{Cu}$ couple. ${ }^{19,20}$ An electrochemical path is established in the graphene/oxide/Cu stack and gives rise to a corrosion rate even higher than that of bare $\mathrm{Cu}$. Therefore, the inhibition of the corrosion lies in the suppression of the electrochemical reaction paths. Researchers have incorporated multilayer graphene oxides or graphene into insulating polymer matrixes to inhibit the electrochemical reaction and enhance the barrier performance. ${ }^{3,21-25}$ However, it involves a complex process and increases the barrier thickness.

Hexagonal boron nitride (BN) has a lattice structure similar to graphene, ${ }^{26}$ ultrathin thickness, high resistivity, ${ }^{27}$ excellent thermal conductivity, ${ }^{28}$ air-stability, ${ }^{29,30}$ and high impermeability. ${ }^{9,31-33}$ Liu et al. showed excellent barrier performance of $\mathrm{BN}$, which can effectively protect $\mathrm{Ni}$ from oxidation at the temperature of $1100{ }^{\circ} \mathrm{C}$ for a short term..$^{32} \mathrm{Li}$ et al. demonstrated strong oxidation resistance of BN sheets on short-term heating. ${ }^{30}$ Researchers also studied the corrosion-resistance of BN coated $\mathrm{Cu}$ foil for 200 hours, and revealed that the BN coating increases the open circuit potential of $\mathrm{Cu}$ foil. ${ }^{34}$ However, the long-term anti-corrosion performance of the $\mathrm{BN}$ barrier has 
remained unexplored at the current stage. Also, the barrier performance of $\mathrm{BN}$ and graphene has not been comparatively studied yet.

In this work, we perform first-principles calculations to theoretically evaluate the impermeability of a BN monolayer to oxygen. The barrier performance of BN and graphene is experimentally compared by electrochemical, morphological, and spectroscopic characterization. Monolayer BN shows much better long-term corrosion barrier performance than graphene, which is attributed to the inhibition of galvanic reaction because of high insulating properties of BN.

\section{Experiment details}

The self-consistent field calculation was conducted with a Quantum ESPRESSO.$^{35}$ The distances between a graphene/BN plane and an oxygen molecule varied from $2.78 \AA$ to $0 \AA$ A The $4 \times$ 4 conventional unit cell was used for graphene and $\mathrm{BN}$. The convergence threshold on total energy is $10^{-6}$ and the one on forces is $10^{-3}$ (both in a.u.). The kinetic energy cutoff for wavefunctions was 50 Ry (Rydberg unit of energy, 1 Ry $=13.6$ $\mathrm{eV})$, and the kinetic energy cutoff for charge density and potential was $200 \mathrm{Ry}$.

The electrochemical characterization was performed by a CHI660 electrochemical workstation. A BN/Cu, G/Cu or b/Cu sample was used as the working electrode with a graphite bar as the counter electrode and a calomel electrode as the reference electrode. The electrolyte was $0.1 \mathrm{M} \mathrm{NaCl}$ solution. For Tafel analysis, the scanning rate was $10 \mathrm{mV} \mathrm{s}^{-1}$ and the scan step was $1 \mathrm{mV}$. A small voltage perturbation $(10 \mathrm{mV})$ was used in the EIS measurement. The EIS results were analysed with Zview software.

Bare $\mathrm{Cu}$ foil (bCu), G/Cu and $\mathrm{BN} / \mathrm{Cu}$ were dipped into a $1.0 \mathrm{M}$ $\mathrm{HNO}_{3}$ solution for $15 \mathrm{~min}$. The SEM characterization and the energy dispersive X-ray spectroscopy (EDS) were conducted using a JEOL Model JSM-6490 microscope. The acceleration voltage was kept at $20 \mathrm{kV}$ and the working distance was $10 \mathrm{~mm}$.

The $\mathrm{BN} / \mathrm{Cu}$ and $\mathrm{G} / \mathrm{Cu}$ were exposed to the ambient environment for 160 days. The surface morphologies of the samples were studied with optical microscope (OM, Leica DM1750M) and SEM. The corroded $\mathrm{Cu}$ samples were characterized by Raman, SEM and XPS methods. A Raman spectrometer with an excitation wavelength of $488 \mathrm{~nm}$ was used to study the atomic vibration of $\mathrm{Cu}$ oxides. The power of the laser was $50 \mathrm{~mW}$. A Lorentzian peak fitting method was applied to find the peak height for the peak at $218 \mathrm{~cm}^{-1}$. For XPS, all scans were performed with the angle between the normal of the thin $\mathrm{Cu}$ foil and the detector fixed at $45^{\circ}$. The step of the scanning was 0.25 $\mathrm{eV}$. The deconvolution was done using XPSPEAK4.1 software. A Shirley background was used for the curve fitting. The X-ray diffraction (XRD) data were acquired using a Rigaku SmartLab diffractometer with the scanning step of 0.1 degree. For the samples after 160 day aging, the peaks around 61.7 (PDF\# 653288), 65.9 (PDF\# 48-1548), and 66.5 (PDF\# 48-1548) degrees can be classified to $\mathrm{Cu}_{2} \mathrm{O}(220), \mathrm{CuO}(022)$ and $\mathrm{CuO}(310)$ structures, respectively.

\section{Results and discussions}

\subsection{Density functional theory calculations}

Theoretical calculations have been extensively performed to show the impermeability of graphene to most of the molecules, atoms, and ions. ${ }^{36-39}$ However, the barrier potential for $\mathrm{O}_{2}$ to pass through BN layers has not been calculated. The potential barrier for $\mathrm{O}_{2}$ to pass through graphene and $\mathrm{BN}$ was calculated through the density functional theory (DFT). Fig. 1a shows that the potential barriers for $\mathrm{O}_{2}$ through the "hollow" site of $\mathrm{BN}$ and graphene are around $30 \mathrm{eV}$ and $35 \mathrm{eV}$, respectively. This extremely high potential barrier prohibits $\mathrm{O}_{2}$ from passing through the "hollow" site of BN or graphene. The calculation results for the "bridge" site (Fig. 1b) show that the potential barrier is quite large, around $100 \mathrm{eV}$ for both $\mathrm{BN}$ and graphene. Our first-principles calculations show high impermeability of BN barriers comparable to that of graphene.

When $\mathrm{O}_{2}$ approaches the graphene or BN surface, the dense electron cloud of the two-dimensional (2D) barrier layer forms a strong repelling field and blocks the $\mathrm{O}_{2}$ translocation. In Fig. 1a and b, we find that the potential barriers of graphene are higher than those of BN by $\sim 5 \mathrm{eV}$ on both "hollow" and "bridge" sites. We attribute this to the electron density difference between graphene and BN. Owing to the different element configurations and crystal parameters in graphene and $\mathrm{BN}$, the electrons of graphene are relatively uniformly distributed, while the electron clouds in $\mathrm{BN}$ are densely distributed around $\mathrm{N}$ atoms. ${ }^{40}$ At the "bridge" site, the electron density of graphene is higher than that of BN, and the "hollow" site of BN has larger "pore" and lower electron density than graphene. In addition, the potential barrier at the "bridge" site is almost three times larger than that at the "hollow" site, because of the presence of much higher electron density at the "bridge" site. The potential barriers of graphene and $\mathrm{BN}$ for $\mathrm{O}_{2}$ are both 2 and 3 magnitudes greater than the thermal energy of $\mathrm{O}_{2}(26 \mathrm{meV})$ at room
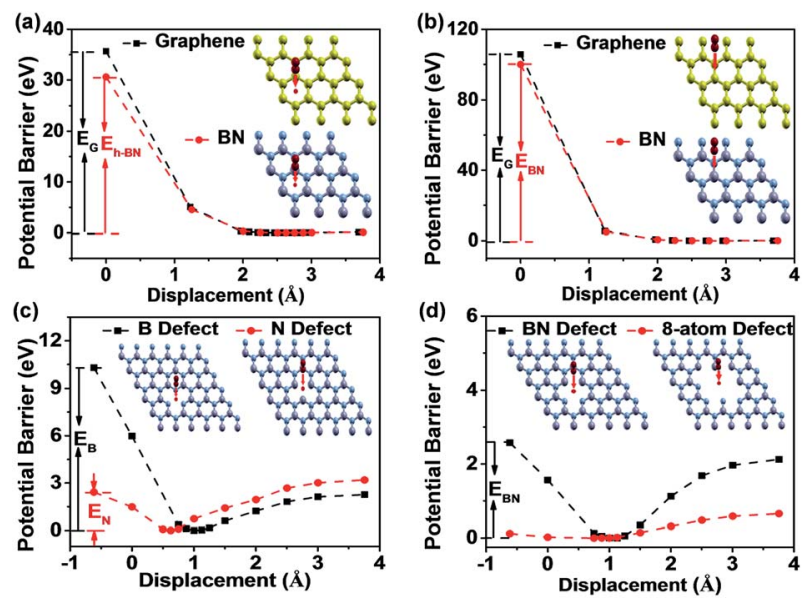

Fig. 1 Potential barriers of $\mathrm{O}_{2}$ penetrating through (a) the "hollow" sites and (b) the "bridge" sites of graphene and BN. (c) The potential barrier of $\mathrm{O}_{2}$ passing through $\mathrm{BN}$ with single $\mathrm{B}$-atom or $\mathrm{N}$-atom defect. (d) The potential barrier of $\mathrm{O}_{2}$ through a BN plane with one $\mathrm{B}-\mathrm{N}$ defect and 8-atom defects. 
temperature. Thus, it is reasonable to expect that the graphene and $\mathrm{BN}$ are both good $\mathrm{O}_{2}$ barrier materials.

The $\mathrm{B} / \mathrm{N}$ stoichiometry of the $\mathrm{BN}$ by the CVD method is generally less than 1 in XPS analysis. ${ }^{41,42}$ For the CVD grown BN on copper foil, the defective sites in $\mathrm{BN}$ allow $\mathrm{O}_{2}$ to react with $\mathrm{Cu}$ and result in oxidation. ${ }^{34}$ Here we use DFT calculations to study the impermeability of defected $\mathrm{BN}$ against $\mathrm{O}_{2}$. For single-atom defect of $\mathrm{BN}$, there are two possible defective sites, namely single B-atom defect and N-atom defect. The inset of Fig. 1c shows the schematic diagram of the defective BN barrier, where an $\mathrm{O}_{2}$ molecule vertically passes through the defective $\mathrm{BN}$ plane. The potential barriers for the $\mathrm{BN}$ with single $\mathrm{B}$-atom and single $\mathrm{N}$-atom are different. For the $\mathrm{BN}$ with a single $\mathrm{B}$-atom defect, the potential barrier increases as $\mathrm{O}_{2}$ approaches the BN plane, as depicted in Fig. 1c. The barrier height is around $11 \mathrm{eV}$, much greater than the thermal energy of $\mathrm{O}_{2}$ at room temperature. The $\mathrm{BN}$ monolayer with single B-atom defect is still impermeable to $\mathrm{O}_{2}$. For the BN with single $\mathrm{N}$-atom defect, the barrier height is about $3 \mathrm{eV}$ (Fig. 1c). This indicates that $\mathrm{O}_{2}$ also has a low probability of passing through the $\mathrm{BN}$ plane. The different results of the two types of defects can be explained by the electron structures of B and N. A N atom has greater electron density than a B atom. ${ }^{40}$ In the case of single B-atom defect, the dense electron cloud of the three surrounding $\mathrm{N}$ atoms overlaps with the electrons of $\mathrm{O}_{2}$ and induces the large barrier potential. For the single N-atom defect case, the energy is lowered because the $\mathrm{N}$ atom with higher electron density is removed. We also performed DFT calculation for the BN monolayer with one pair of $\mathrm{B}-\mathrm{N}$ defect (Fig. 1d). The minimum potential point is around $1 \AA$ away from the basal plane and the potential barrier is around $2 \mathrm{eV}$. Compared with the results for single B-atom defect, the sample with one pair of B-N defect has lower barrier energy. We further expand the defect sites, as shown in Fig. 1d. For the 8-atom defect situation, the barrier height is lowered to around $0.1 \mathrm{eV}$, which means that the highly defective BN surface is not an effective barrier against $\mathrm{O}_{2}$.

\subsection{Short-term corrosion test}

Monolayer graphene and BN were fabricated by the chemical vapour deposition (CVD) method on $\mathrm{Cu}$ foil. The characterization of monolayer graphene and BN by Raman spectroscopy (HORIBA HR800), X-ray photoelectron spectroscopy (XPS, ULVAC-PHI Quantum 2000) and atomic force microscopy (AFM, SPA-400) can be found in Fig. S1 and S2. $\dagger$ The Raman peak of $\mathrm{BN}$ is located around $1369 \mathrm{~cm}^{-1}$, in agreement with the previous results on monolayer $\mathrm{BN} .{ }^{43,44}$ The XPS spectrum shows that the $\mathrm{N} / \mathrm{B}$ ratio is around 1.07. The thickness of the $\mathrm{BN}$ is measured by AFM, less than $0.52 \mathrm{~nm}$. These results demonstrate high-quality monolayer graphene and BN.

We first conducted an acidic corrosion test to evaluate the barrier performance of graphene and $\mathrm{BN}$ monolayer. Bare $\mathrm{Cu}$ foil $(\mathrm{bCu})$ and $\mathrm{Cu}$ foils with graphene $(\mathrm{G} / \mathrm{Cu})$ and with $\mathrm{BN}(\mathrm{BN} /$ $\mathrm{Cu}$ ) coating were dipped into a $\mathrm{HNO}_{3}$ solution. The scanning electron microscopy (SEM) images, and XPS and Raman spectra of the samples before and after the corrosion test are shown in
Fig. S3. $\uparrow$ The results exhibit that graphene and BN can effectively protect the underlying $\mathrm{Cu}$ foil for a short-term.

An electrochemical corrosion test was conducted to quantitatively compare the barrier performance of the graphene and BN samples in a relatively short term. The corrosion penetration rates $(\mathrm{CPR})$ of $\mathrm{G} / \mathrm{Cu}, \mathrm{BN} / \mathrm{Cu}$ and $\mathrm{bCu}$ samples are calculated according to the equation: ${ }^{45}$

$$
\mathrm{CPR}(\mathrm{mm} \text { per year })=0.327 \times \frac{10^{-3} M i_{\text {corr }}}{m \rho}
$$

where $M$ is the molar mass $\left(\mathrm{g} \mathrm{mol}^{-1}\right), m$ is the valence, $\rho$ is the density of the material $\left(\mathrm{g} \mathrm{cm}^{-3}\right)$, and $i_{\text {corr }}$ is the corrosion current density $\left(\mathrm{mA} \mathrm{m}^{-2}\right)$. The corrosion current densities are about 40.0, 31.3 and $316 \mathrm{~mA} \mathrm{~m}^{-2}$, and the extracted CPR values are about $0.036,0.046$ and $0.360 \mathrm{~mm}$ per year for the $\mathrm{G} / \mathrm{Cu}, \mathrm{BN} /$ $\mathrm{Cu}$ and bCu samples, respectively. The corrosion resistance of the $\mathrm{G} / \mathrm{Cu}$ and $\mathrm{BN} / \mathrm{Cu}$ are similar. The small $E_{\text {corr }}$ shift (Fig. 2a) also indicates that the susceptibilities of the $\mathrm{G} / \mathrm{Cu}$ and $\mathrm{BN} / \mathrm{Cu}$ samples to the electrochemical oxidation are approximately the same. ${ }^{18}$ Graphene shows a significant passivation effect in short-term heating test ${ }^{2}$ and electrochemical test. ${ }^{16-18}$ The mass transport through the $\mathrm{BN}$ or graphene lattice becomes a rate limiting factor of corrosion due to their high impermeability.

We found that the equilibrium potential $\left(E_{\mathrm{eq}}\right)$ shifts to the positive direction by around $50 \mathrm{mV}$ when the graphene or $\mathrm{BN}$ barriers are present, as shown in Fig. S4. $\dagger$ This feature has also been reported by Prasai et al. and Raman et al. ${ }^{17,18}$ The positive shift can be caused by the $\mathrm{Cu}$ concentration difference at the working electrodes. Under low concentration conditions, the Nernst half-cell equations can be expressed as: ${ }^{46}$

$$
E_{\text {eq }}=E_{\text {eq }}^{0}+\frac{59}{m} \log \left(n_{\text {ions }}\right)
$$

where $E_{\mathrm{eq}}$ is the equilibrium potential, $E_{\mathrm{eq}}^{0}$ is the equilibrium potential under standard conditions, $m$ is the valence number ( 2 for $\mathrm{Cu}^{2+}$ and 1 for $\mathrm{Cu}^{+}$), and $n_{\text {ions }}$ is the concentration of $\mathrm{Cu}$ ions between $2 \mathrm{D}$ barrier layer and $\mathrm{Cu}$. It is found that the concentration of the $\mathrm{Cu}$ ions in the $\mathrm{G} / \mathrm{Cu}$ and $\mathrm{BN} / \mathrm{Cu}$ samples is 50 times as much as that in the bCu sample. The $\mathrm{Cu}$ ions are generated by the galvanic corrosion. However, the 2D barrier inhibits the migration of $\mathrm{Cu}$ ions through it, and prevents the
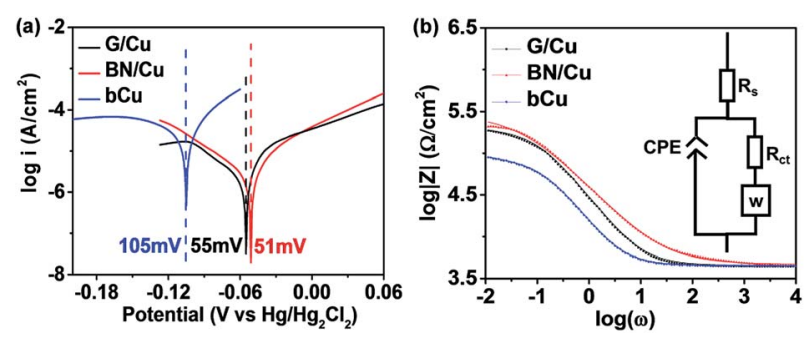

Fig. 2 (a) The Tafel plot of the BN/Cu, G/Cu, and bCu samples. The equilibrium potential shifts to the positive direction by around $50 \mathrm{mV}$ when the graphene or BN barrier is present. (b) The electrochemical impedance spectroscopy (EIS) curve measured for the bCu, BN/Cu and $\mathrm{G} / \mathrm{Cu}$ samples. The inset schematic diagram shows the corresponding Randles-Warburg model. 
formation of oxides. Thus, the $\mathrm{Cu}$ ions accumulate between the $2 \mathrm{D}$ barrier and $\mathrm{Cu}$, and the concentration of $\mathrm{Cu}$ ions at the interface increases accordingly, which further retards the electrochemical reaction.

The Randles-Warburg model can be used to explain the corrosion mechanism of uncoated metals. We use the model for the $\mathrm{BN} / \mathrm{Cu}$ and $\mathrm{G} / \mathrm{Cu}$ samples, as shown in the equivalent circuit in Fig. $2 \mathrm{~b},{ }^{17}$ where $R_{\mathrm{S}}$ is the solution resistance, and CPE (constant phase element) represents the capacitance between the metal and the solution. We can translate the CPE to double layer capacitance $\left(C_{\mathrm{dl}}\right)$. A Warburg element $(W)$ accounts for the semi-infinite diffusion between thin $\mathrm{Cu}$ foil and electrolyte. $R_{\mathrm{ct}}$ is the resistance due to the charge transfer between the metal and the solution. ${ }^{17,47}$

According to Wang et al., the protective coatings with high $R_{\mathrm{ct}}$ and low $C_{\mathrm{dl}}$ values are considered to provide good anticorrosion performance, because $R_{\mathrm{ct}}$ measures the resistance to aggressive species transfer, and $C_{\mathrm{dl}}$ reflects the water uptake tendency of coatings. ${ }^{47,48}$ The extracted $C_{\mathrm{dl}}$ and $R_{\mathrm{ct}}$ parameters according to the model are documented in Table S1. $\uparrow$ The $C_{\mathrm{dl}}$ of the $\mathrm{BN} / \mathrm{Cu}\left(3.3 \times 10^{-6} \mathrm{~F} \mathrm{~cm}^{-2}\right)$ and $\mathrm{G} / \mathrm{Cu}\left(1.7 \times 10^{-5} \mathrm{~F} \mathrm{~cm}^{-2}\right)$ samples is lower than that of the bCu samples $\left(5.3 \times 10^{-5} \mathrm{~F}\right.$ $\mathrm{cm}^{-2}$ ) by around 16 times and 3 times, respectively. One possible explanation for the significant $C_{\mathrm{dl}}$ difference is that the $\mathrm{G} / \mathrm{Cu}$ or $\mathrm{BN} / \mathrm{Cu}$ structure forms another capacitor in series with the capacitor formed by the electrolyte-electrode interface. ${ }^{17}$ The $R_{\mathrm{ct}}$ of the $\mathrm{G} / \mathrm{Cu}\left(1.75 \times 10^{5} \Omega \mathrm{cm}^{-2}\right)$ and $\mathrm{BN} / \mathrm{Cu}\left(2.79 \times 10^{5}\right.$ $\left.\Omega \mathrm{cm}^{-2}\right)$ samples is greater than that of the bCu samples $(7.71 \times$ $10^{4} \Omega \mathrm{cm}^{-2}$ ) by around 2 times and 4 times, respectively, showing the high resistivity of $\mathrm{BN}$ and graphene layers to corrosion.

\subsection{Long-term corrosion test}

The foregoing studies have shown that BN exhibits a corrosion barrier performance similar to that of graphene in a short term. To evaluate the long-term corrosion barrier characteristics, the as-grown $\mathrm{G} / \mathrm{Cu}$ and $\mathrm{BN} / \mathrm{Cu}$ samples were kept in the ambient environment at room temperature with a relative humidity of around $60 \%$ for 160 days. Fig. 3a and b are representative optical microscopy (OM) images of the as-prepared $\mathrm{G} / \mathrm{Cu}$ and $\mathrm{BN} / \mathrm{Cu}$ samples, showing uniformly coloured and highly reflective surfaces. This indicates that these two kinds of asprepared samples are free of oxides in the initial stage of the corrosion test. The morphologies of the as-prepared $\mathrm{G} / \mathrm{Cu}$ and $\mathrm{BN} / \mathrm{Cu}$ samples are quite similar to that of the bCu sample because of high optical transmittance of both graphene and BN. However, after a certain period of the corrosion test, the $\mathrm{G} / \mathrm{Cu}$ and BN/Cu samples exhibit distinguished appearances. Fig. 3c shows a representative $\mathrm{OM}$ image of the $\mathrm{G} / \mathrm{Cu}$ sample after exposure to the ambient environment for 80 days, which exhibits highly inhomogeneous corrosion, agreeing well with previous reports. ${ }^{19,20}$ The $\mathrm{Cu}$ corrosion is initiated from the defective sites of the graphene barrier. Around $65 \%$ of the observed area is corroded. In contrast, the $\mathrm{BN} / \mathrm{Cu}$ sample remains protected with few $\mathrm{Cu}$ grains showing different colours (Fig. 3d). For the G/Cu sample after 120 day corrosion (Fig. 3e),
Sample: $\mathrm{G} / \mathrm{Cu}$ Sample: BN/Cu

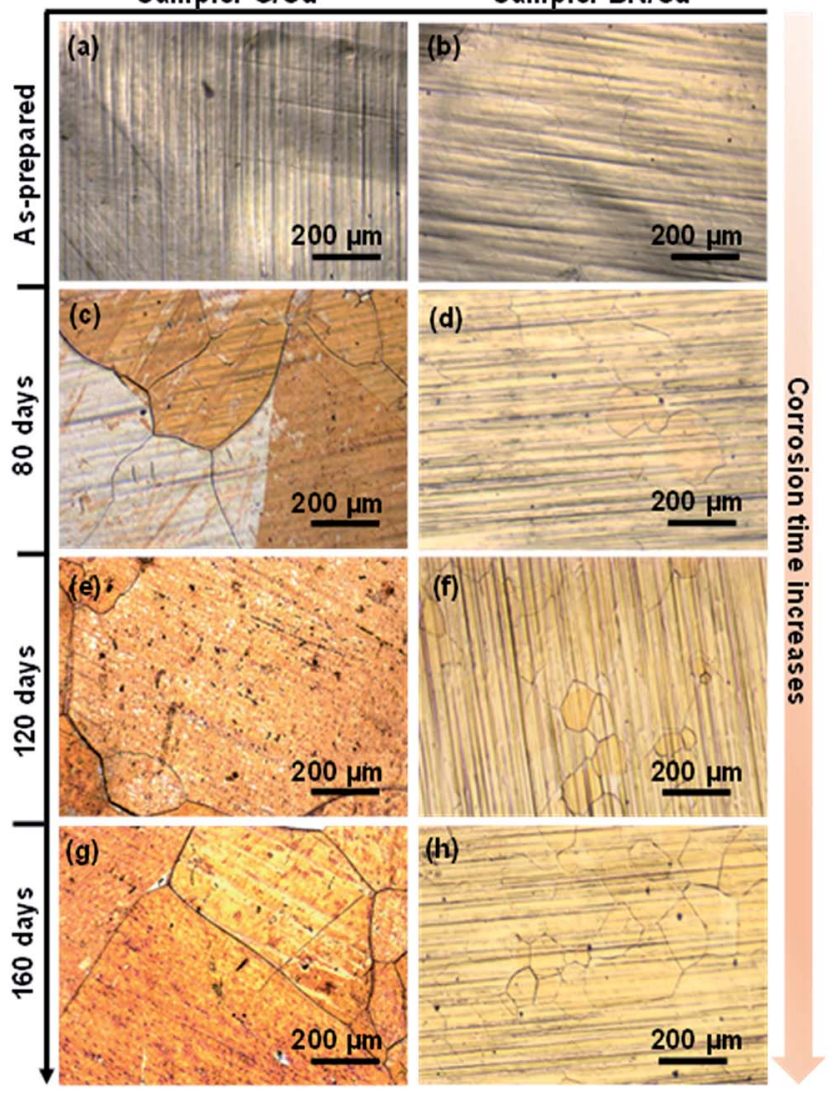

Fig. 3 Optical microscopy images of G/Cu and BN/Cu. ( $a$ and b) Asprepared samples, (c and d) after 80 days', (e and f) after 120 days' and ( $\mathrm{g}$ and $\mathrm{h}$ ) after 160 days' exposure to the ambient environment.

most of the areas are severely corroded, showing a different morphology from Fig. 3a. A few grains of the $\mathrm{BN} / \mathrm{Cu}$ sample show colour changes but the surface structure of the $\mathrm{BN} / \mathrm{Cu}$ can still be viewed, as depicted in Fig. 3f. The corroded area occupies about $6 \%$ of the whole sample. Compared with the $\mathrm{G} / \mathrm{Cu}$ sample (Fig. 3g), the $\mathrm{BN} / \mathrm{Cu}$ sample shows much less colour change after aging for 160 days, as evidenced in Fig. 3h, almost indistinguishable from the as-prepared $\mathrm{BN} / \mathrm{Cu}$ sample. The lightly corroded area consists of $10 \%$ of the observed region. These results imply that the $\mathrm{BN} / \mathrm{Cu}$ is less severely oxidized than the $\mathrm{G} / \mathrm{Cu}$ after the long-term corrosion test, and $\mathrm{BN}$ is an effective long-term corrosion barrier for $\mathrm{Cu}$.

Fig. $4 \mathrm{a}$ and b show typical SEM images of the as-prepared G/ $\mathrm{Cu}$ and $\mathrm{BN} / \mathrm{Cu}$ samples. The relatively smooth surface can be viewed, in agreement with our optical image characterization. Fig. 4c shows the SEM image of the G/Cu surface after 80 day aging. The grain boundary in the middle separates the figure into two parts. In the left region, some small white regions can be observed, which is different from the morphology of Fig. 4a due to the oxidation. In Fig. 4d, we find that most of the area is homogeneously colored with a small region at the lower left hand side non-uniformly colored. After exposure to the ambient environment for 120 days and 160 days, the black-white regions consist of most of the $\mathrm{G} / \mathrm{Cu}$ sample and can be clearly viewed (Fig. 4e and g). Based on the morphology change, almost all the 
Sample: $\mathrm{G} / \mathrm{Cu}$

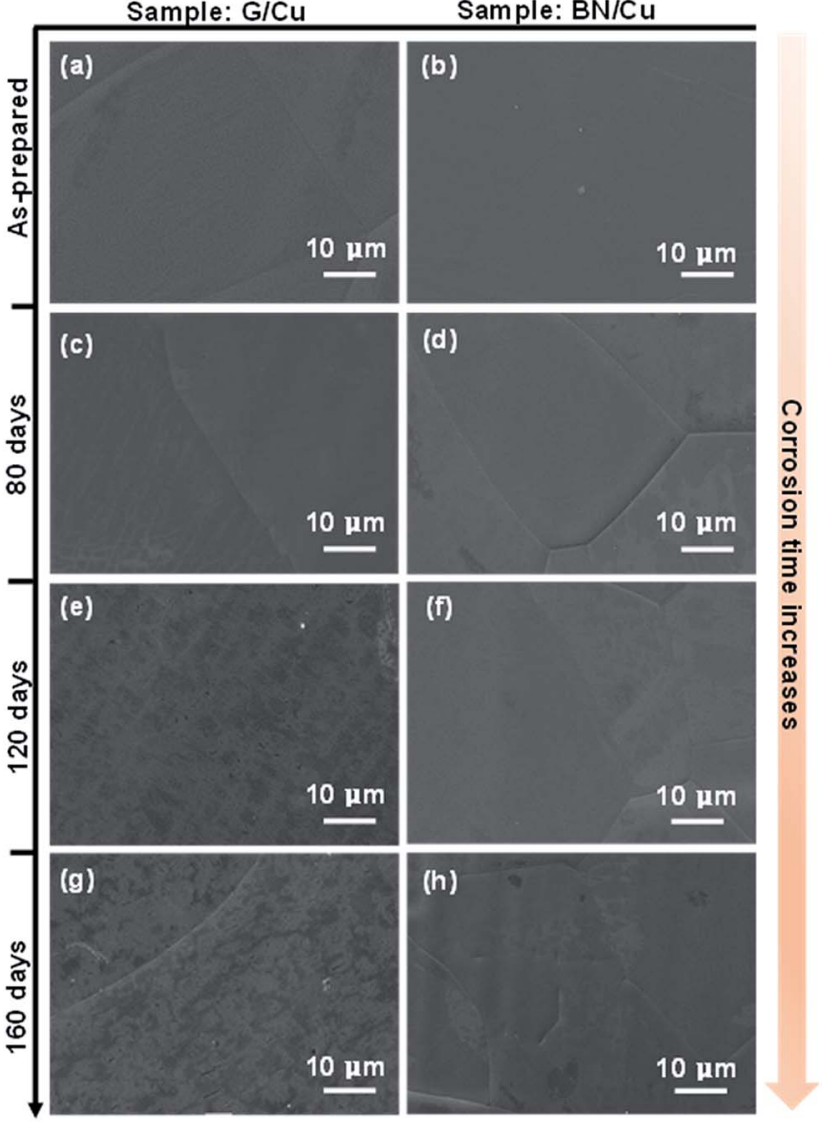

Fig. 4 Scanning electron microscopy images of the G/Cu and the BN/ Cu samples. (a and b) As-prepared samples, (c and d) after 80 days', (e and f) after 120 days' and ( $g$ and h) after 160 days' exposure to the ambient environment.

detected area is found to be severely oxidized. The surface inhomogeneity is very likely to be caused by the formation of $\mathrm{Cu}$ oxides according to this series of observation. This indicates that $\mathrm{G} / \mathrm{Cu}$ is more severely oxidized than $\mathrm{BN} / \mathrm{Cu}$. For the $\mathrm{BN} / \mathrm{Cu}$ after long-term exposure, the surface is still relatively homogeneous with little black-white mixed regions (Fig. 4f and h). These striking differences show that $\mathrm{BN} / \mathrm{Cu}$ is more resistant to corrosion in an ambient environment than $\mathrm{G} / \mathrm{Cu}$.

The Raman spectra of the G/Cu and BN/Cu were monitored during the long-term corrosion tests, as shown in Fig. 5a-c. From the Raman spectrum of the as-prepared sample in Fig. 5a, we can observe negligible peaks of $\mathrm{Cu}$ oxides, indicating that the as-prepared $\mathrm{G} / \mathrm{Cu}$ and $\mathrm{BN} / \mathrm{Cu}$ samples are almost pristine, exhibiting good consistency with our optical and SEM characterization. Fig. $5 \mathrm{~b}$ shows the Raman spectrum after 80 day exposure to ambient conditions. Two pronounced peaks at 218 $\mathrm{cm}^{-1}$ and $644 \mathrm{~cm}^{-1}$ can be detected on the G/Cu sample, corresponding to the $\mathrm{Cu}_{2} \mathrm{O}$ peaks. ${ }^{49}$ In contrast, insignificant changes can be observed for the $\mathrm{BN} / \mathrm{Cu}$ sample at this stage. After 160 day exposure to the ambient environment, more Raman peaks emerge for the $\mathrm{G} / \mathrm{Cu}$ sample, as shown in Fig. 5c. The peaks at $218 \mathrm{~cm}^{-1}, 414 \mathrm{~cm}^{-1}$ and $644 \mathrm{~cm}^{-1}$ correspond to the $\mathrm{Cu}_{2} \mathrm{O}$ peaks, ${ }^{49}$ and the peaks at $300 \mathrm{~cm}^{-1}$ and $500 \mathrm{~cm}^{-1}$ (a)

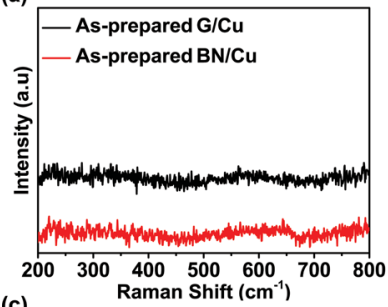

(c)

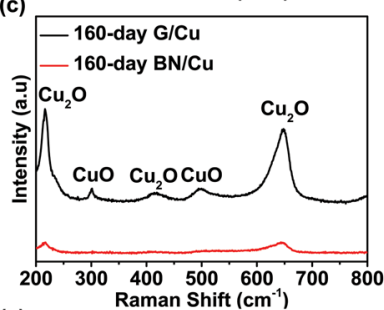

(e)

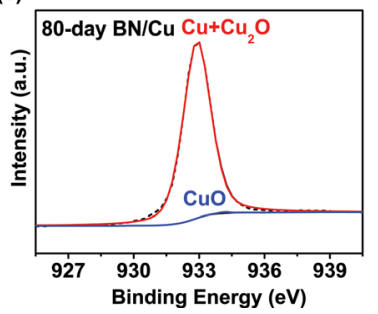

(b)

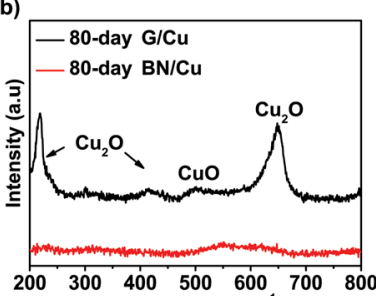

(d)
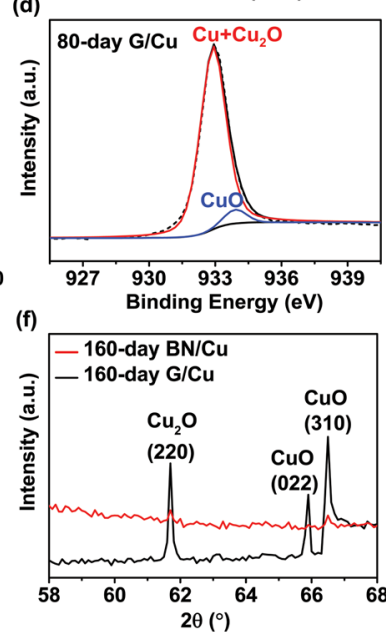

Fig. 5 Raman spectra of G/Cu and BN/Cu samples: (a) as-prepared, (b) 80 day aging, and (c) 160 day aging. XPS spectra of (d) the G/Cu sample and (e) the BN/Cu sample after 80 day aging with peak deconvolution. (f) XRD graph of the $\mathrm{G} / \mathrm{Cu}$ and $\mathrm{BN} / \mathrm{Cu}$ samples after 160 day aging.

result from $\mathrm{CuO}^{50}$ Although the $\mathrm{Cu}_{2} \mathrm{O}$ peaks at $218 \mathrm{~cm}^{-1}$ and $644 \mathrm{~cm}^{-1}$ are also observed in the BN/Cu sample after 160 day exposure, the intensity is much weaker than that in the $\mathrm{G} / \mathrm{Cu}$ sample.

Fig. $5 \mathrm{~d}$ and e show representative XPS data of the $\mathrm{G} / \mathrm{Cu}$ and $\mathrm{BN} / \mathrm{Cu}$ samples after 80 day exposure. The binding energy of $\mathrm{Cu}^{2+}$ is $933.9 \mathrm{eV}$, around $1 \mathrm{eV}$ greater than that of $\mathrm{Cu}$ atoms and $\mathrm{Cu}^{+}{ }^{51} \mathrm{The}^{\mathrm{Cu}^{2+}}$ percentage of the $\mathrm{G} / \mathrm{Cu}$ sample is $3 \%$ (Fig. $5 \mathrm{~d}$ ), comparable to the result reported by Zhou et al. ${ }^{20}$ In comparison, the $\mathrm{Cu}^{2+}$ percentage drops to $0.2 \%$ for the $\mathrm{BN} / \mathrm{Cu}$ sample (Fig. 5e). Similar XPS results were also obtained for 160 day samples, as shown in Fig. S5. $\dagger$ The X-ray diffraction (XRD) has a higher penetration depth than the XPS method. Fig. $5 \mathrm{f}$ shows the XRD patterns of the $\mathrm{G} / \mathrm{Cu}$ and $\mathrm{BN} / \mathrm{Cu}$ samples after 160 day aging. In the $\mathrm{G} / \mathrm{Cu}$ sample, the peaks around $61.7,65.9$, and 66.5 degrees can be assigned to $\mathrm{Cu}_{2} \mathrm{O}(220)$, $\mathrm{CuO}(022)$ and $\mathrm{CuO}$ (310), respectively. However, for the BN/Cu sample, insignificant peaks of oxide can be observed. These results confirm that the $\mathrm{BN} / \mathrm{Cu}$ sample is better protected after long-term corrosion.

\subsection{Anti-corrosion mechanisms of a BN barrier}

The oxidation of $\mathrm{Cu}$ thin films at room temperature was previously studied by Cabrera et $a l .{ }^{52} \mathrm{Cu}$ functions as a cathode in the electrochemical cell, providing electrons to ionize oxygen molecules and forming oxides at the surface of $\mathrm{Cu}$. The electrons tunnel through the oxide layer on the $\mathrm{Cu}$ surface and react 
(a) $\mathrm{G} / \mathrm{Cu}$

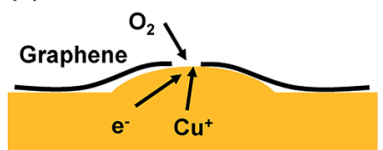

(c)
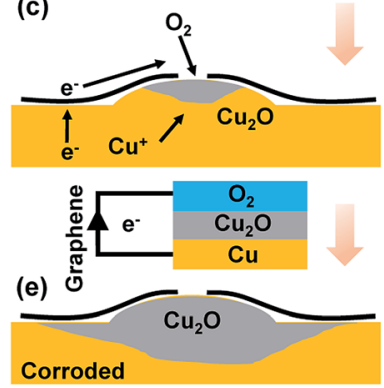

(b) BN/Cu

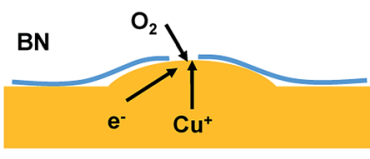

(d)

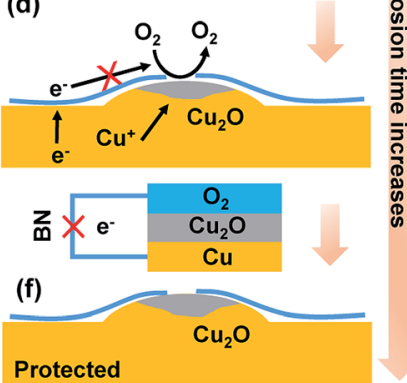

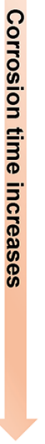

Fig. 6 Schematic diagrams of the corrosion mechanisms in the BN/ $\mathrm{Cu}$ and $\mathrm{G} / \mathrm{Cu}$ samples. The defective sites in the (a) graphene and (b) BN samples allow the unprotected $\mathrm{Cu}$ to react with $\mathrm{O}_{2}$ and eventually form oxides for both the $\mathrm{G} / \mathrm{Cu}$ and BN/Cu samples. (c) The highly conductive graphene can transport electrons to oxygen atoms, working as the cathode in the electrochemical circuit. (d) The electrochemical circuit for the BN/Cu sample is open because $\mathrm{BN}$ is electrically insulating. Equivalent circuit for the (e) G/Cu and (f) BN/Cu samples.

with oxygen. The electron tunnelling is highly dependent on the oxide depth. The oxidation rate slows down significantly as the thickness of the insulating oxidation layer increases, because few electrons can tunnel through the oxidation layer to complete the reaction.

For the $\mathrm{G} / \mathrm{Cu}$ and $\mathrm{BN} / \mathrm{Cu}$ samples, the defective sites in the $2 \mathrm{D}$ barrier allow the unprotected $\mathrm{Cu}$ to react with $\mathrm{O}_{2}$ and form oxides (Fig. 6a and b). For both samples, the transport of electrons through $\mathrm{Cu}$ is blocked as the $\mathrm{Cu}_{2} \mathrm{O}$ layer grows. However, the graphene barrier provides another conduction path for electrons to reach oxygen because it possesses high electrical conductivity. The conductivity of graphene is significantly higher than that of $\mathrm{BN}$ in the horizontal direction. The highly conductive graphene can transport electrons to oxygen atoms, working as the cathode for the galvanic reaction (Fig. 6c). The corrosion region expands in both horizontal and vertical directions, as illustrated in Fig. 6e. For the BN/Cu sample, the electron transport in the horizontal direction is prohibited because it is electrically insulating, in which the close loop of an electrochemical cell is disconnected and the corrosion is slowed down, as depicted in Fig. 6d and $\mathrm{f}$. Therefore, the BN/Cu shows higher oxidation resistance than the $\mathrm{G} / \mathrm{Cu}$.

\section{Conclusions}

Our theoretical calculation predicts that BN has impermeability similar to that of graphene. An electrochemical test verifies that both $\mathrm{BN}$ and graphene have excellent short-term corrosion resistance. We comparably evaluate the long-term corrosion resistance of $\mathrm{BN}$ and graphene for 160 days. The OM, SEM, Raman, XPS and XRD characterization results show that a BN monolayer has much better long-term corrosion resistance than that of graphene. This excellent barrier performance of a BN monolayer can be understood to be a result of its high insulating characteristics, suppressing the electrochemical reaction. The BN layers can be considered as an alternative ultra-thin barrier to graphene when the conductivity of the protection layer is not important for the application of the device.

\section{Acknowledgements}

This work was supported by the Research Grant Council of Hong Kong (grant number: PolyU 252001/14E); the National Natural Science Foundation of China (grant No. 61302045); and the Hong Kong Polytechnic University (grant numbers: G-UC72, H-ZG1N). Q. Yao and S. Chen are supported by the National Natural Science Foundation (Grants 51302233 and 11374244), and the Specialized Fund for the National Distinguished Dissertation Author (Grant No. 2014043) of China.

\section{Notes and references}

1 S. Bohm, Nat. Nanotechnol., 2014, 9, 741-742.

2 S. Chen, L. Brown, M. Levendorf, W. Cai, S.-Y. Ju, J. Edgeworth, X. Li, C. W. Magnuson, A. Velamakanni, R. D. Piner, J. Kang, J. Park and R. S. Ruoff, ACS Nano, 2011, 5, 1321-1327.

3 D. Kang, J. Y. Kwon, H. Cho, J. H. Sim, H. S. Hwang, C. S. Kim, Y. J. Kim, R. S. Ruoff and H. S. Shin, ACS Nano, 2012, 6, 7763-7769.

4 Y. P. Hsieh, M. Hofmann, K. W. Chang, J. G. Jhu, Y. Y. Li, K. Y. Chen, C. C. Yang, W. S. Chang and L. C. Chen, ACS Nano, 2014, 8, 443-448.

5 Y. D. Zhao, Y. Z. Xie, Z. K. Liu, X. S. Wang, Y. Chai and F. Yan, Small, 2014, 10, 4521-4542.

6 Y. Zhao, Y. Xie, Y. Y. Hui, L. Tang, W. Jie, Y. Jiang, L. Xu, S. P. Lau and Y. Chai, J. Mater. Chem. C, 2013, 1, 4956-4961.

7 Y. Zhao, Y. Xie, Z. Bao, Y. H. Tsang, L. Xie and Y. Chai, J. Phys. Chem. C, 2014, 118, 11827-11832.

8 J. C. Reed, H. Zhu, A. Y. Zhu, C. Li and E. Cubukcu, Nano Lett., 2012, 12, 4090-4094.

9 Q. Cai, L. H. Li, Y. Yu, Y. Liu, S. Huang, Y. Chen, K. Watanabe and T. Taniguchi, Phys. Chem. Chem. Phys., 2015, 17, 77617766.

10 L. Nilsson, M. Andersen, R. Balog, E. Laegsgaard, P. Hofmann, F. Besenbacher, B. Hammer, I. Stensgaard and L. Hornekaer, ACS Nano, 2012, 6, 10258-10266.

11 H. Kim, A. W. Robertson, S. O. Kim, J. M. Kim and J. H. Warner, ACS Nano, 2015, 9, 5947-5957.

12 C. G. Kang, S. K. Lim, S. Lee, S. K. Lee, C. Cho, Y. G. Lee, H. J. Hwang, Y. Kim, H. J. Choi, S. H. Choe, M.-H. Ham and B. H. Lee, Nanotechnology, 2013, 24, 115707.

13 Y. Zhao, Z. Liu, T. Sun, L. Zhang, W. Jie, X. Wang, Y. Xie, Y. H. Tsang, H. Long and Y. Chai, ACS Nano, 2014, 8, 12601-12611.

14 C. P. Y. Wong, T. J. H. Koek, Y. P. Liu, K. P. Loh, K. E. J. Goh, C. Troadec and C. A. Nijhuis, ACS Appl. Mater. Interfaces, 2014, 6, 20464-20472.

15 W. K. Morrow, S. J. Pearton and F. Ren, Small, 2015, 12, 120134. 
16 N. T. Kirkland, T. Schiller, N. Medhekar and N. Birbilis, Corros. Sci., 2012, 56, 1-4.

17 D. Prasai, J. C. Tuberquia, R. R. Harl, G. K. Jennings and K. I. Bolotin, ACS Nano, 2012, 6, 1102-1108.

18 R. K. S. Raman, P. C. Banerjee, D. E. Lobo, H. Gullapalli, M. Sumandasa, A. Kumar, L. Choudhary, R. Tkacz, P. M. Ajayan and M. Majumder, Carbon, 2012, 50, 40404045.

19 M. Schriver, W. Regan, W. J. Gannett, A. M. Zaniewski, M. F. Crommie and A. Zettl, ACS Nano, 2013, 7, 5763-5768.

20 F. Zhou, Z. Li, G. J. Shenoy, L. Li and H. Liu, ACS Nano, 2013, 7, 6939-6947.

21 Y.-H. Yang, L. Bolling, M. A. Priolo and J. C. Grunlan, Adv. Mater., 2013, 25, 503-508.

22 O. C. Compton, S. Kim, C. Pierre, J. M. Torkelson and S. T. Nguyen, Adv. Mater., 2010, 22, 4759-4763.

23 W. Sun, L. Wang, T. Wu, M. Wang, Z. Yang, Y. Pan and G. Liu, Chem. Mater., 2015, 27, 2367-2373.

24 H. Kim, Y. Miura and C. W. Macosko, Chem. Mater., 2010, 22, 3441-3450.

25 K. Choi, S. Nam, Y. Lee, M. Lee, J. Jang, S. J. Kim, Y. J. Jeong, H. Kim, S. Bae, J. B. Yoo, S. M. Cho, J. B. Choi, H. K. Chung, J. H. Ahn, C. E. Park and B. H. Hong, ACS Nano, 2015, 9, 5818-5824.

26 C. R. Dean, A. F. Young, I. Meric, C. Lee, L. Wang, S. Sorgenfrei, K. Watanabe, T. Taniguchi, P. Kim, K. L. Shepard and J. Hone, Nat. Nanotechnol., 2010, 5, 722726.

27 K. Watanabe, T. Taniguchi and H. Kanda, Nat. Mater., 2004, 3, 404-409.

28 D. Golberg, Y. Bando, Y. Huang, T. Terao, M. Mitome, C. Tang and C. Zhi, ACS Nano, 2010, 4, 2979-2993.

29 Y. Chen, J. Zou, S. J. Campbell and G. Le Caer, Appl. Phys. Lett., 2004, 84, 2430-2432.

30 L. H. Li, J. Cervenka, K. Watanabe, T. Taniguchi and Y. Chen, ACS Nano, 2014, 8, 1457-1462.

31 E. Husain, T. N. Narayanan, J. J. Taha-Tijerina, S. Vinod, R. Vajtai and P. M. Ajayan, ACS Appl. Mater. Interfaces, 2013, 5, 4129-4135.

32 Z. Liu, Y. Gong, W. Zhou, L. Ma, J. Yu, J. C. Idrobo, J. Jung, A. H. MacDonald, R. Vajtai, J. Lou and P. M. Ajayan, Nat. Commun., 2013, 4, 2541.

33 M. Yi, Z. Shen, X. Zhao, S. Liang and L. Liu, Appl. Phys. Lett., 2014, 104, 143101.

34 L. H. Li, T. Xing, Y. Chen and R. Jones, Adv. Mater. Interfaces, 2014, 1, 1300132.

35 P. Giannozzi, S. Baroni, N. Bonini, M. Calandra, R. Car, C. Cavazzoni, D. Ceresoli, G. L. Chiarotti, M. Cococcioni,
I. Dabo, A. Dal Corso, S. de Gironcoli, S. Fabris, G. Fratesi, R. Gebauer, U. Gerstmann, C. Gougoussis, A. Kokalj, M. Lazzeri, L. Martin-Samos, N. Marzari, F. Mauri, R. Mazzarello, S. Paolini, A. Pasquarello, L. Paulatto, C. Sbraccia, S. Scandolo, G. Sclauzero, A. P. Seitsonen, A. Smogunov, P. Umari and R. M. Wentzcovitch, J. Phys.: Condens. Matter, 2009, 21, 395502.

36 M. Topsakal, H. Sahin and S. Ciraci, Phys. Rev. B: Condens.

Matter Mater. Phys., 2012, 85, 155445.

37 O. Leenaerts, B. Partoens and F. M. Peeters, Appl. Phys. Lett., 2008, 93, 193107.

38 L. Tsetseris and S. T. Pantelides, Carbon, 2014, 67, 58-63.

39 M. E. Suk and N. R. Aluru, J. Phys. Chem. Lett, 2010, 1, 15901594.

40 S. Hu, M. Lozada-Hidalgo, F. C. Wang, A. Mishchenko, F. Schedin, R. R. Nair, E. W. Hill, D. W. Boukhvalov, M. I. Katsnelson, R. A. W. Dryfe, I. V. Grigorieva, H. A. Wu and A. K. Geim, Nature, 2014, 516, 227-230.

41 K. K. Kim, A. Hsu, X. Jia, S. M. Kim, Y. Shi, M. Hofmann, D. Nezich, J. F. Rodriguez-Nieva, M. Dresselhaus, T. Palacios and J. Kong, Nano Lett., 2012, 12, 161-166.

42 Y. M. Shi, C. Hamsen, X. T. Jia, K. K. Kim, A. Reina, M. Hofmann, A. L. Hsu, K. Zhang, H. N. Li, Z. Y. Juang, M. S. Dresselhaus, L. J. Li and J. Kong, Nano Lett., 2010, 10, 4134-4139.

43 L. H. Li, E. J. G. Santos, T. Xing, E. Cappelluti, R. Roldan, Y. Chen, K. Watanabe and T. Taniguchi, Nano Lett., 2015, 15, 218-223.

44 R. V. Gorbachev, I. Riaz, R. R. Nair, R. Jalil, L. Britnell, B. D. Belle, E. W. Hill, K. S. Novoselov, K. Watanabe, T. Taniguchi, A. K. Geim and P. Blake, Small, 2011, 7, 465468.

45 H. A. Barham, S. A. Brahim, Y. Rozita and K. A. Mohamed, Int. J. Electrochem. Sci., 2011, 6, 181-198.

46 R. W. Revie, Corrosion and Corrosion Control, John Wiley \& Sons, 2008, p. 25.

47 M. D. Wang, M. Y. Liu and J. J. Fu, J. Mater. Chem. A, 2015, 3, 6423-6431.

48 J. Fu, T. Chen, M. Wang, N. Yang, S. Li, Y. Wang and X. Liu, ACS Nano, 2013, 7, 11397-11408.

49 H. Gao, J. Zhang, M. Li, K. Liu, D. Guo and Y. Zhang, Curr. Appl. Phys., 2013, 13, 935-939.

50 M. H. Chou, S. B. Liu, C. Y. Huang, S. Y. Wu and C. L. Cheng, Appl. Surf. Sci., 2008, 254, 7539-7543.

51 Z. H. Gan, G. Q. Yu, B. K. Tay, C. M. Tan, Z. W. Zhao and Y. Q. Fu, J. Phys. D: Appl. Phys., 2004, 37, 81-85.

52 N. Cabrera and N. F. Mott, Rep. Prog. Phys., 1949, 12, 163184. 